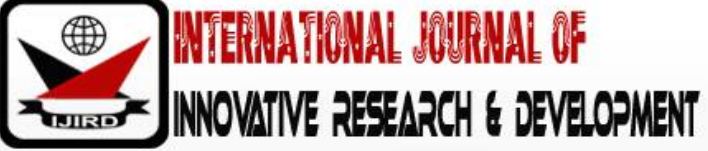

ISSN 2278 - 0211 (Online)

\section{Health Vulnerability to Climate Mitigation among Women in the North West Region: The Case of Ngwo- Njikwa Sub Division, Nigeria}

\author{
Dr. Lucy Fonjong Udikoh \\ Senior Lecturer, Department of Anthropology, University of Yaounde I (Cameroon)
}

\begin{abstract}
:
This is an ethnographic study which dwells on literary and field data gathered on climate change and vulnerability issues in Momo Division of the North West region of Cameroon among the Ngwo community. It demonstrates the contribution of socio-cultural grip on the woman in climate change and susceptibility paradigm shift as she plays her role in humanity. In acquiring the necessary qualitative data, we used documentations, life-stories, interviews, focus groups and observation and free listing. The goal of this study is to expose constrains of women in rural areas in the social system despite women enabling. Looking at our study community, our data reveals that there is need for universal cultural knowledge through information that should be guided to enhance social change and adaptability. Besides, basis for the universality of human rights should both be moral and normative.Meanwhile, rural sustainable development is highly recommended.
\end{abstract}

Keywords: Impact, climate change, vulnerability, social change

\section{Introduction}

Many women around the world have got to become used to with their lives to a varying weather. As increase in severe climate situation droughts, storms, and floods are currently changing economies, economic growth, and patterns of human movement, and are likely to be in the midst of the major universal health fear in this century. Thus every person will be affected by these changes, but not uniformly. Susceptibility to weather alteration will be strong-minded by a group of people or individual's capability to become accustomed. Since studies have shown that women excessively experience the impacts of disasters, harsh climate actions, and weather change because of cultural norms and the unbalanced allocation of roles, resources, and power, especially in developing countries. To this effect, lack of self-government and choice building power, limit women's ability to adapt to climate change. Meanwhile, women often have little or no power over family finances and possessions. In many communities, like our case of study, women are under figure in community politics, and thus have little weight over community strategies to become use to and over policies that support women's rights and priorities. Without contribution by women, programs to reinstate traditional crops with those better wellmatched to the changing atmosphere, might focus only on the needs of men's fields and not address the harms women face with household gardens.

Meanwhile, cultural margins on mobility can hinder women to get in touch with information and services. Also, during severe weather actions, women may not be able to put something in a new place without the say-so of a male relative. Traditional clothing may hold back women's ability to run or swim, making it harder for them to getaway disasters. Meanwhile, women who have lost clothing in disasters may be less likely to access food and medical aid because they are unable to enter public areas. However, when one look at the situation in the Ngwo community of the North West region of Cameroon, the following could be attributed to be responsible for the problems of women's vulnerability with climate change, a precondition for sustainable, effective and competent development is the application of extension services; and as a result, educating professional and non professional women and performing developmental programs for female farmers could be encouraged. This is aimed at women gaining access to extensional services, communicating with women group and encouraging female farmers to participate at extensional activities programs.

\section{Methodology}

Our study population consists of the 16 quarters of Ngwo village which was randomly selected after an analytic scientific compilation of extensive field data and other materials gathered on gender - marriage and reproductive issues in Momo Division of the North West region. After exploring documents from research centers like SIL, IFORD, etc, we exploited the internet and got information from articles, books and other information on the theme of gender climate change and vulnerability. With adequate information from documentaries, we proceeded for fieldwork in the above 
mentioned area, specifically in the Ngwo community. Preliminary visits and discussions were done on the subject before intensive fieldwork. Our informants were from the ages of 25 and above and were questioned for about one hour and at least thirty minutes. Meanwhile they had the freedom to talk without divergence on the subject research on, though some emphasized on their poor harvest due to climatic changes. At least 200 persons were questioned out of 300 who were solicited since some of them did not respect appointments due to other engagements. Men and women were interviewed and we used the purpose sampling in collecting our data. In all we had 50 men and 150 women to talk with. 05 focus groups were held with 12 members in the highest populated and 06 members recorded in the least populated. Farmers groups were the greatest source of information. All respondents who were interested were questioned without discrimination of religion, class or profession. This permits us to collect dynamic views to enrich our data. Periods of transhumance like summer holidays and development meetings were equally exploited.

\section{Presentation of Research Area}

This study is focus on the Ngwo community of Momo Division in the North West region.The Ngwo village is located in Njikwa sub-division, found in Momo division of the North West province of Cameroon. This highland region lies approximately between latitudes $6^{\circ} 5^{\prime}$ and $6^{\circ}$ 17' North of the equator and between longitudes 9o $14^{\prime}$ and 9० 55' East of the Greenwich Meridian. From the 1987 population and housing census, Ngwo had 7454 inhabitants and this population has since then increased and is today spatially distributed within 16 quarters.

This region constitutes a mosaic of grassland and forest cover, as this is a contact zone between the Western Grassfield and the Manyu forest area. The alternation between forest and grassland offers a good ground for agro-pastoral activities. The main livestock reared here consist of cattle, sheep and goats. Land degradation is less felt in Lower Ngwo due to the flat nature of the terrain and less human activities except towards the foot of the Mbando and Mfoh hills where the situation reverses. The frequent occurrence of landslides around Mbando and Mfoh has forced the inhabitants to migrate to the neighbouring Ako and Angar quarters respectively. This was due to the constant loss of lives and property. The present sites of these quarters are not quite far from their former sites and so there is a level of vulnerability to overburden released from the overlying slopes.

This constitutes seven (7) quarters stretching from Nkwo right to Andondo and these quarters are aligned along the slopes overlying the Nkwo River. While the slopes are usually above $40 \%$ in gradient highly weathered due to abundance of rainfall. Such has permitted the formation of abundant soil or overburden that is easily displaced in case of any triggering factor such as heavy rainfall or intense human activities. Soh, Sabri and Nkwo quarters are highly vulnerable to landslides and this claim lives and property yearly. This is as a result of the steep slope gradient that worsens the occurrence of slope movements with time as the years go by; landslide seems to increase within this area. Njam and Agi bridges have often suffered destruction from the passage of landslides debris. The road to Menka was completely cut off on many spots after the 2002 landslides occurrences. The inhabitants of these steep slopes are equally exposed to the effects of violent monsoon winds that have often destroyed houses and crops.

With that said, some of the factors generally affecting women include:

\section{Women's Vulnerable Health}

According to WHO Report (1995), women bear the greatest burden of health problems than men and these health problems in many communities not excluding the Ngwo community are attached to pregnancy and delivery complications. In addition, women suffer from unsaved abortions, miscarriages and even in surviving pregnancies; they bear most of the weight of conception. This does not end at the level of carrying the pregnancy for many months which is risky, since women are exposed to contracting STI and suffering from difficulties of reproductive tract infections. Bringing up children is also a very, very tedious but practical activity of the woman. With that image in view, below are some factors responsible for the poor health situation of the Ngwo woman. Economic hardship is one of the causes of women's health as put forward by (Beijing, 1995). As a result of this, it was estimated that a majority of 1.5 billion people living in extreme poverty are women. In many sectors women are likely to be poorer than men due to gender discrimination. So, poor women live on poor diet both in quantity and quality and during pregnancy it can be very dangerous to the unborn child. Poverty in some areas, limits the girl's child from furthering education and this reduces her chances to get out of poverty and poor health. The reason for this is because an educated person could easily change his/ her status by hard work. An example of such cases has been demonstrated by a family whose intention is to give their children different trade so as to reduce their level of poverty.

With the hard times we are passing through these days; it is not possible for us to send all our children to school. We have therefore preferred our daughters to learn a trade so that she could easily assist the family in the nearer future by caring for their juniors to go further said a lady. Fieldwork 2016.

Still, according to the Beijing Declaration of (1995), pregnancy and children favours or increases women's health risk socially. This is seen in the sense that mortality and morbidity are as a result of work stress or load incurred by women. Coupled to this, a number of women especially the poor usually get into risky relationships which could result to pregnancy. When this happens, unsaved abortions are being carried out which endanger their health. Although some few women have a knowledge and use pills as a method of contraceptive, this reduces the livelihood of a pregnancy, thus affecting fertility.

Sometimes streams that flow across villages serves for cooking and drinking up stream while the downstream serves as toilet. Many people fail to know that these streams flow through many villages and served the same purpose thus this, expose the community to health dangers. Also, poor conditions of cooking are a hazard to the health of a woman. Evidence is from WHO (1986) who pointed out that indoor cooking is another social and environmental cause of women's 
health risk. Many Ngwo women are involved in preparing the meals of the family regularly; consequently many suffer from constant and continuous poor conditions which are at times a problem to their health.

In most communities where people are educated especially women, decision taking and self dependency is prevalent. This is not because gender bias does not exist but simply because, women could know and see what is very good for them especially in reproductive health matters. Thus, the above situation could be well managed when opportunities arises. Possible ideas or suggestions over living standards could be better handled and solved by women. In Ngwo community, women mostly find it difficult to make such decision since their husbands are mostly the ones responsible for bills. It may not really be easy to propose any contrary environment given their lack of means.

Health exposure is in connection to physical or psychological danger to women's reproductive safety coupled to the possibility of coping with these threats. Therefore, in relation to our study, the concept of health fitness and desirable conduct depends on the state institution available in the area. Thus, the context of disease and disability are linked to the cultural circumstances within which human problems are marked out. On another page, many people especially the people of Ngwo do not accept certain diseases as illness except the illness occur frequently. In economic terms, health care is necessary to keep the human capital needed for the running of the society. This means that it is better to make a living and unity in a society when someone is in a good health state than when sick. Under harsh climatic women carry out certain tasks like carrying water from long distances due to persistent dryness and this could have complications in childbearing.

This implies that the health of an individual is based on attitude and knowledge. That is the more reason why, many cases in our case study do not see some illnesses as need to go to the hospital until further notice or when signs of risk develop. This could lead to complications especially when the right diagnosis and treatments are not administered. An example of this is the manifestation of malaria in a pregnant woman. When these symptoms do not persist, malaria in the Ngwo community is seen as normal even in children. In any case, the people of Ngwo believed that for a child to change a stage in growth he/ she must be feverish so as to empty the body to enter a new stage.

Though this could be perceived to be normal according to their belief system, high malaria in a pregnant woman could result to a miscarriage. Therefore, there is a need for the right diagnosis to be done and for treatment to follow. In connection to the above, HIV/ AIDS is one of the most dangerous diseases ravaging many lives in the world today, with the Ngwo community as one of such that suffer from this and other STI such as gonorrhoea, syphilis, it is because sexuality is one of their problems. As a matter of fact, due to the poor way in which sexual life is managed amongst members of this society one can easily be confronted with such diseases. However, mismanagement is likening to the fact that cultural norms relating to sex do not favour the woman. Modern methods of contraception are not well used or even known by many. Consequently, this causes reproductive health difficulties to many. Therefore there is a problem of knowledge attitude and practice to be redressed.

Socially, women need a lot to do with their feeding. Lack of food and equitable distribution of food in the household is a situation which needs to be looked upon as indicated by (World Bank (1992). Among the people of the Ngwo community, preferences in relation to food distribution begin from childhood. This is a disadvantage to the girl child in the sense that men and boys feed on the best quality and quantity of food prepared in the homes while the girl children feed on leftovers and in season of poor harvest many women and children go malnourish. This ought to be the contrary due to the reproductive role a female child has to exercise in the society. In most cases, women suffer from malnutrition when they do not take many calories to support the energy exhausted especially during the performance of their triple role of farming, cooking and childbearing. These are very tedious duties which need great equilibrium and food balance. It should be understood that malnutrition obstruct labour, thus, making the woman liable or subject to infection, anaemia and haemorrhage which could even result to death.

According to Filgueira, 1998, p. 123-129), social vulnerability is that which make people more susceptible to conditions of unemployment, insecurity, and poverty. It is also widely applied to specific groups of the population women, children, and the elderly - who are thought to be more susceptible than others to certain phenomena, such as illness or maltreatment. On a population, (Ford, 2002) Social scientists, particularly in Latin America, apply the concept to the conditions forced upon some social groups due to structural adjustments and macroeconomic changes. The term vulnerability has various meanings. Etymologically it means to be susceptible to become hurt, to receive a blow, physically or morally. In more general terms, it refers to the property of materials, human individuals, social groups, complex systems, etc., which turns them unstable under the action of external disturbances (Ford, 2002).

\section{Impact of Climate Change on Ngwo women}

Besides socio-cultural and psychological impact witnessed, natural factors are equally affecting the Ngwo people and women in particular. Current climate change primarily the release of carbon dioxide and other greenhouse gases from human activities such as the building of fossil fuel, loss of forest, etc in the industrial world hits many world's population today. Therefore the Ngwo women in the face of such circumstances undergo dynamism so as to adapt to the changing environment. Some of which come in with very harsh health conditions hence could bring instability as well which are discussed below.

It has been generally acknowledged that increasing water levels coupled with climate change will give way to an increase in water borne diseases. Other feasible health penalty of climate change include higher rates in malnutrition due to food shortages, increase in heat-related mortality and morbidity, and increase in respiratory disease where air contamination is worsened. Children under five are the main victims of sanitation-related illnesses, and -along with the elderly-are most affected by heat stress (Bartlett 2008). In this wise, gender discrimination in the distribution of resources, including those relating to nutrition and medicines, may put girls at greater risk than boys. This is because even in times of shortage, the cultural notion among the Ngwo people is to see the father's plate full even if it meant others 
should go without food. Consequently, there is need for more research into the gender-specific health impacts of climate change on the children and adolescents so that it would help to shed light on the scope to which this is the case, and would in turn enable a more targeted response.

Issues such as health are being affected during climate change in that persisting heat causing high evaporation of water. This can result to an increase in infectious water borne or vector borne diseases. An example is malaria due to increased temperatures and intensified storms. These aspects which we have experienced for quite sometime in our country in towns like Yaounde and Douala are equally found in the localities. Cholera is one of such water born diseases that has caused persistent havoc in the city as well. Malaria is not only a bad disease but very dangerous to a pregnant woman as it could result to a miscarriage if not well treated. In relation to our area of study, Ngwo women who avoided health care services such as hospitals due to negligence, see the need to change from such negative habits.

In addition to the above point, heat related illness and malnutrition are faced due to climate change. An example of such case is the situation of the colocosia crop which has known very high price due to poor produce since 2009. High prices have caused many low income earners to move away from the consumption of the product. Consequently, poor feeding, could lead to malnutrition since this is one of their main food crop. It should be noted that the colocosia plant constitute one of the staple food of the Ngwo people back home which is highly cultivated. The tendency here is that the community sell this food to town dwellers and in turn use the money to meet other home needs. With the sky-rocking price, many people turn to drop this food production due to seedlings shortage, thus reducing income flow which the Ngwo people obtain to meet both health and social needs.

Besides, persistent dryness which is often experienced in rural areas especially the case of 2009, which lead to an increase in air pollution leading to air borne diseases such as cough, cold, etc (Source : fieldwork 2011). Consequently, many people were victims of poor health given that human activities such as car driving, farming, etc raised a lot of dust in the air. Thus, the people using mostly untarred roads faced such health difficulties. More over, high temperatures especially at night, causes sleepless nights and stress that gives way to mental disorders such as anxiety and depression.

Although the above points are generally raised as some of the natural implications in rural life which contribute to health hazards, the following affect women directly or indirectly. This is specific because our topic deals with feminist issues and women are mostly affected due to the reproductive role they play in our society.

To begin with, pregnant and lactating women along with the very young and old are the most vulnerable to health threats. This is because women suffering from cough or cold easily affect the baby especially during lactation. Therefore preventive measures need to be put forward with considerations of mother and child since the mother is also the closest person to younger ones in times of nursing, bathing or sickness.

More over, due to natural settlements which at times cause unhealthy and dangerous water shortage as well as sanitation as people share their water sources with animals such as cattle. The case of informal settlement which people built on risky or endangered land for example such areas mostly during the rainy seasons vulnerable to landslide. As well, people under our case of study mostly depend on unreliable water source especially as many lack portable water to carry on with their house chores activities, like other town women, except for drinkable water that is considered portable since it passes through natural rocks. Such sources of water carry water borne diseases like Typhoid or dysentery. Consequently, it can be a problem to children, as they may not be easily sensitive to this, since children could drink anything they see as water to satisfy their thirst when they are thirsty. So, this endangers life.

One of the disturbing factors rose on gender, health and climate change is the fact that women and girls are usually expected to take care after the sick, especially in times of disasters and environmental stress. Economic wise, these hinder them and limit the time they have accessible for income generation which, when attached with increasing medical costs in addition to family illnesses heighten levels of economic deficiency. By so doing, they become less able to contribute to community-levels decision-making processes on climate change or disaster drop. As if these are not enough, the load of looking after dependents while being indebted to trek further for water or food or firewood makes women and girls lying face down to stress-related illness and tiredness. (Voluntary Services Overseas 2006; CIDA 2002).

Besides, women and girls encounter barriers due to a decline in food security and livelihood opportunities that can also cause considerable stress for men and boys, given socially ascribed expectation that will provide economically for the household. This means that failure in food crops can drop the provision of the home by a husband or a lack from his debtor thus causing an economic disability in the home. At times, this can lead to mental illness in some persons. It has been recognised that men and boys are less likely to seek help for stress and mental health issues than women and girls (Masika 2002). This means that preparation for, and responses to climate change need to be sensitive to gender differentials in healthcare (including mental) seeking behaviour. Stress is likely heightened after disaster, particularly where families are displaced and have to live in emergency or transitional houses. Overcrowding, lack of privacy and collapse of regular routines and livelihood patterns can contribute to anger, frustration and violence, with children (especially girls) and women most vulnerable (Barlett 2008).

\section{Coping Strategies to Climate Change and Vulnerability}

Though climate change contact on women are many, it is necessary to say that worldwide, women play a vital role in the organization, preservation and use of natural resources. This is seen in their crucial task for growing food, collecting water and fuel wood. Consequently, they are zealously aware of their environments and the distressing impacts of deforestation, desertification and other forms of environmental ruin. Therefore even in integral issues to marriage, reproductive health or climate, it is necessary to put women at the front position and encourage change through capacity building. 
By so doing, women in their own way will avoid such poor environmental disturbances, by trying to solve some of these problems so as to adapt to change. In order to have good water, available, unclear sources such as wells are being boiled before drinking or treated with chemicals. Boiling according to the Ngwo people, must go for many hours just as they prepare food like corn so as to make sure all the micros are killed. This helps to fight against poor health conditions such as water born diseases usually common in many areas.

The need for individual houses with latrines and other personal sanitation activities is lacking. This makes life complicated as some use streams, pork holes or nature to be at ease. Individuals here know they need to avoid contracting diseases from other people. For this, avoidance to them would mean if there is a sickness, it should be from the house and not from outside the home and therefore they could be able to bear. Yet uncovered toilets encourage flies that carry diseases and contaminate food.

As far as high temperatures are concerned many children and women abandon sitting rooms to stay out of the house to take fresh air in their corridors or play under the moonlight or trees, for some areas that have such amenities just as it is the culture Some even take such opportunities to sing, dance or tell stories. Meanwhile, during the day, they bathe on several occasions or hide in tree sheds, while many children go naked.

Furthermore, food storage is maximised during periods of abundance and are kept for future or scarce periods. Here, Ngwo women prepare local bans like digging the ground to store cocoyam in times of plenty so as to use when high prices are faced. Also things like corn, beans are bought during low prices and preserved using local leaves like cypress leaves to avoid insects from destroying and consumed during scarcity. Meanwhile, okra is bought in times of plenty and dried for future usage. These practices are done to complement their meals and food nutrients during seasons of deficiency or high prices in these items.

\section{Conclusion}

By agreeing that women are a vulnerable group, there is therefore need for them to be protected from many forms of illnesses. One of the reasons why women's health needs to be taken care of is the fact that she has a specific role in the society which is related to her health that is reproduction. The care women need is suppose to be collaborative efforts in order to better address the problem. From this study the causes of illness among women vary. This variation includes social causes like illiteracy, poor sanitation conditions and the non-availability of appropriate health institutions as health units have poor functioning health system with weak referral system especially during obstetric and neonatal emergencies. Also reference health units are far with very bad roads to get there.

Economically this vulnerability is further exacerbated by the workload and tedious activities carried out by the woman. Women in theNgwo community lack roads to farms and to markets, consequently, they travel for very long distances to the farms and are forced to carry heavy load for subsistence farming and marketing. They are equally unable to be medically attained to in cases of illness as a result poor financial output from their activities.

Culturally linked to this is the fact that a woman by traditions and values has as an obligation to submitting to her husband even at her own health risk and this need to be considered. Such pressures even knowing the behaviour of partners makes life difficult especially in a case of multiply sexual partners on the part of the husband. A community like Ngwo in this way refuses women's right to equity and bias is broad. In most cases, women's combined biological and social vulnerability to sexual and reproductive health problems. It is through that means that they need to be able to exercise choice in their sexual and reproductive lives. But precisely it is in this area that the promotion for the ability to choose-that human rights instruments, particularly those relating to reproductive rights, play a central role. Improvement in women's health requires more than better science and health care. Beyond this, it also requires state action to correct injustices to women and to help create the enabling conditions necessary to fully exercise these rights.

It is therefore necessary that the basis for the universality of human rights should both be moral and normative. By virtue of natural law, every individual should posses certain fundamental freedoms. The normative foundation of universality stems from the universal acceptance of human rights by members of the community of states. While universality is the rule, where there is room for variation in the way human rights are implementing in accordance with national, regional, historical, cultural, and religious characteristics. It is the duty of states, however, regardless of their political, economic, and cultural systems, to promote and protect all human rights and fundamental freedoms, including reproductive rights. The implementation of human rights is also subject to supervision by impartial, independent international bodies rather than by individual states themselves.

\section{References}

i. Care International, "Adaptation, Gender and Women's Empowerment," Care International Climate Change Brief (2010), accessed at www.careclimatechange.org/files/adaptation/CARE_Gender_Brief_Oct2010.pdf, on Oct. 16, 2012.

ii. Care International, (2010), "Adaptation, Gender and Women's Empowerment," Care

iii. CARE International, (2010), "Adaptation, Gender and Women's Empowerment."

iv. CIDA, (2002). Takes Action against HIV/ AIDS Around the world, June 2002.

v. Collins, B.(2008). Dark Pursuit. Grand Rapids, Mich: Zonderven.

vi. Delor, F. et Hubert, M. (2000). Revising the concept of vulnerability. Centre d'études Sociologique, faculté universitaires Saint-Louis, 43. Primitive Concepts of Disease." University of California.

vii. Eric Neumayer and Thomas Plümper, (2007) "The Gendered Nature of Natural Disasters: The Impact of Catastrophic Events on the Gender Gap in Life Expectancy, 1981-2002," Annals of the Association of American Geographers 97, no. 1: 551-66. 
viii. Filgueria, (1998). El “Problema” del embarazo adolescente, Colegio de Mexico.

ix. Ford, J. (2002. Standing Committee on legislation session report: an overview of the thirty-sixth parliament, May, 2001 to August 9, 2002. Western Australia, Legislative Council.

x. International Climate Change Brief (2010), accessed at www.careclimatechange.org/ files/ adaptation/CARE Gender Brief Oct2010.pdf, on Oct. 16, 2012.

xi. Masika, R.(2002), Editorial in, Gender, Development and Climate Change", (Masika, R. Ed., Oxfam Gender and Development Journal, Volume 10 Issue 2.

xii. Mutunga Cliff and Hardee Karen,(2010): "Population and Reproductive Health in National Adaptation Programmes of Action (NAPAs) for Climate Change in Africa," African Journal Reproductive Health 14, no. 4, 12739.

xiii. UN Population Fund (UNFPA), State of the World Population: Women, Population and Climate Change (New York: UNFPA, 2009).

xiv. UNFPA, State of the World Population: Women, Population and Climate Change.

xv. Voluntary Service Overseas (VSO, 2006), Reducing the Burden of HIV and AIDS Care on Women and Girls, Voluntary Services Overseas (VSO0 Policy Brief, UK: VSO.

xvi. World Bank,(1992), Governance and Development, Washington, DC, The World Bank.http:/ / doc.wb.org/ curated/ en/ 1992/ 04/ 40582/ governance-development.

xvii. World Health Organization (WHO, 2011). Gender, Climate Change and Health (Geneva: World Health Organization, 2011). 